\title{
Investigation of the Pore Structure of Tight Sandstone Based on Multifractal Analysis from NMR Measurement: A Case from the Lower Permian Taiyuan Formation in the Southern North China Basin
}

\author{
Kaixuan $Q u^{1,2}$ and Shaobin Guo ${ }^{1,2, *}$ \\ 1 School of Energy Resources, China University of Geosciences (Beijing), Beijing 100083, China; \\ Qukx159357@163.com \\ 2 Key Laboratory of Strategy Evaluation for Shale Gas, Ministry of Land and Resources, Beijing 100083, China \\ * Correspondence: guosb58@cugb.edu.cn
}

Received: 28 June 2020; Accepted: 30 July 2020; Published: 6 August 2020

\begin{abstract}
Understanding the pore structure can help us acquire a deep insight into the fluid transport properties and storage capacity of tight sandstone reservoirs. In this work, a series of methods, including X-ray diffraction (XRD) analysis, casting thin sections, scanning electron microscope (SEM), nuclear magnetic resonance (NMR) experiment and multifractal theory were employed to investigate the pore structure and multifractal characteristics of tight sandstones from the Taiyuan Formation in the southern North China Basin. The relationships between petrophysical properties, pore structure, mineral compositions and NMR multifractal parameters were also discussed. Results show that the tight sandstones are characterized by complex and heterogenous pore structure, with apparent multifractal features. The main pore types include clay-dominated micropores and inter- and intragranular dissolution pores. Multifractal parameters of sandstone samples were acquired by NMR and applied to quantitatively describe the pore heterogeneity in higher and lower probability density regions (with respect to small and large pore-scale pore system, respectively). The multifractal parameter $\left(D_{-10}\right)$ of lower probability density areas has better correlation with the petrophysical parameters, which is more suitable for evaluating the reservoir properties of tight sandstone. However, the multifractal parameter $\left(D_{10}\right)$ of higher probability density areas is more conducive to characterize the pore structure of tight sandstone. Additionally, the mineral compositions of sandstone have a complex effect on multifractal characteristics of pores in different probability density areas. The $D_{10}$ increases with the decrease of quartz content and increase in clay mineral content, whereas $D_{-10}$ decreases with the increase in clay minerals and decrease of authigenic quartz content and feldspar content.
\end{abstract}

Keywords: tight sandstone; pore structure; heterogeneity; NMR measurements; multifractal analysis

\section{Introduction}

Due to their huge geological reserves and wide distributions, tight sandstone gas greatly alleviates the contradiction between the world's increasing demand on energy and the depletion of conventional resources [1]. In China, tight sandstone gas reservoirs are characterized as one with the porosity and permeability less than $10 \%$ and $0.1 \mathrm{mD}$, respectively [2], and these tight reservoirs require extensive hydraulic fracture or special gas extraction techniques to achieve commercial production [3]. In comparison with conventional sandstones, the pore structures of tight sandstones are usually more complex and heterogeneous, because of their various pore size (nano-scale to micro-scale), poor connectivity and irregular pore geometry [4-7]. The pore structure replaces porosity and 
permeability as the critical parameter for the evaluation of reservoir properties, as it not only controls gas storage and transport mechanisms, but also determines the displacement efficiency and recovery rate of hydrocarbon in the tight sandstone reservoirs [6-9]. Consequently, detailed characterizations of pore structure are necessary procedures for understanding the producibility of tight sandstone gas reservoirs.

A variety of analytical methods have been geared to qualitatively and quantitatively characterize the pore structure of tight sandstone, such as casting thin sections (CAT), scanning electron microscopy (SEM), mercury injection porosimetry (MIP), gas absorption [10,11], X-ray computed tomography (XCT) [12] and nuclear magnetic resonance (NMR). Among them, NMR is a convenient and non-damaging method for characterizing the pore structure and pore fluids in the rock. In NMR experiments, proton ${ }^{1} \mathrm{H}$ (abundant in water and hydrocarbon) can generate a dipole moment in the presence of an external magnetic field. The signal amplitude of dipole moment is in proportion to the number of protons within pore fluids $[13,14]$. Thus, NMR is able to characterize petrophysical properties, the saturation of different types of pore fluids (movable fluids, bound fluids and hydrocarbons) and pore size distributions (PSD) of the reservoir rocks [15].

In the past few decades, numerous studies demonstrated that fractal theory is another robust tool for the characterization of pore structure in the porous media, including sedimentary rock, soil, concrete and other materials [16-21]. Fractal geometry successfully builds a bridge between petrophysical properties and microstructures of reservoir rocks, and a single fractal dimension, $\mathrm{D}$, have been introduced to describe the fractal behavior and geometric irregularity of pore structure [22-24]. As a complex geological material, the PSD curves of tight sandstones often show "fluctuations" and "jumps" at different pore size intervals, and fractal characteristics vary greatly among different pore size intervals, which cannot be explained by a single fractal dimension [25]. The reason is that the single fractal dimension can only describe the irregularity and complexity within the specific pore size intervals. Multifractal theory is an extension of single fractal theory, which can offer more precise information about pore structure by resolving multifractal structure into a set of intertwined fractal subsets [26]. Nowadays, multifractal analysis has become a widely used mean to analyze the pore structure of coal, shale, and carbonate reservoirs [25,27-31]. Nevertheless, only a little attention has been given to the pore structure of tight sandstone [32,33]. Hence, multifractal analysis based on NMR experiment provides a brand-new perspective on the nature of pore structure and heterogeneity in tight sandstone reservoirs.

In this work, a case study from the Lower Permian Taiyuan Formation $\left(\mathrm{P}_{1} \mathrm{t}\right)$ tight sandstones in the southern North China Basin was conducted to investigate pore structure features by various methods. Multifractal analysis was implemented to quantify the heterogeneity of pore structure in different probability density areas, based on $\mathrm{NMR} \mathrm{T}_{2}$ distributions. Additionally, the relationships between multifractal parameters of different probability density areas and mineralogical compositions, pore structure parameters and petrophysical properties of tight sandstone samples were investigated. This study provides new insights into the microscopic pore structure and heterogeneity of tight sandstone with similar geological conditions.

\section{Geological Setting}

The southern North China basin (SNCB) is a large meso-cenozoic superimposed basin, located in the southern part of the North China plate, with an area of $150,000 \mathrm{~km}^{2}$ (Figure 1) [34]. The basin mainly consists of five secondary tectonic units from north to south, and the present tectonic pattern shows the NW-WNW (Figure 1). 


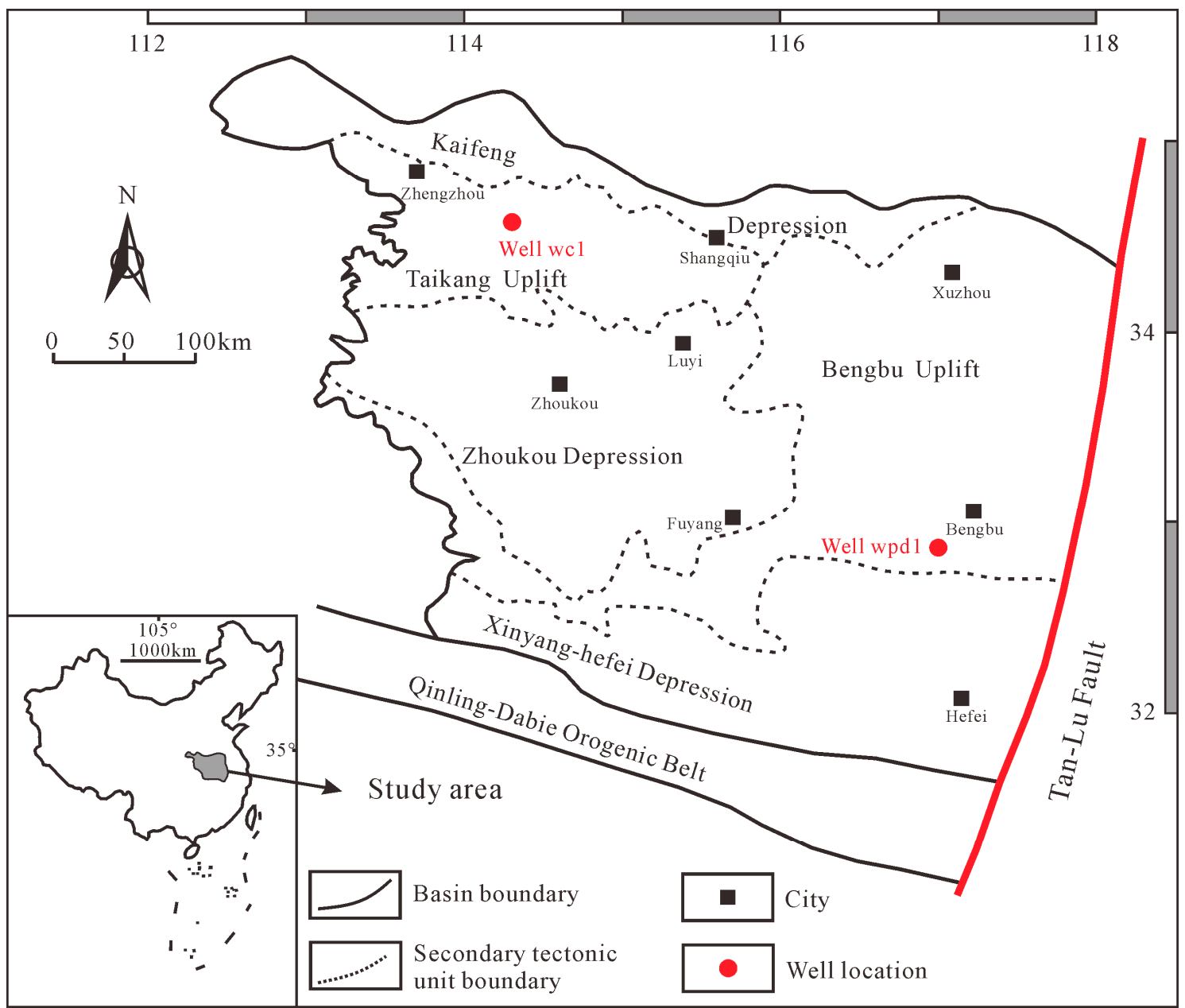

Figure 1. Tectonic geology condition of southern North China basin (SNCB) and investigated well location (adapted from [34]).

The continuous uplift of the entire North China platform during the Caledonian movement led to the absence of the Upper Ordovician, Silurian and Devonian, and Lower Carboniferous strata [35]. From the Late Carboniferous to the Late Permian, affected by the regional tectonic movement, the study area underwent the depositional process from the epicontinental sea to the continental basin (Figure 2) [36]. The Taiyuan Formation $\left(\mathrm{P}_{1} \mathrm{t}\right)$, which is composed of black shale, coal, limestone and sandstone, was deposited during the early Permian, with a thickness of about 30-175 $\mathrm{m}$ (Figure 2) [37]. Sedimentary facies of the Taiyuan Formation are mainly lagoon, tidal flat, barrier island, and carbonate platform (Figure 2). A previous study has shown that shale and coal from Taiyuan Formation possess high organic matter content (TOC), moderate maturity, mainly type III kerogen, and high gas generation potential, which can serve as good source rocks for tight sandstone reservoirs, as well as the potential reservoirs for shale gas and coal bed methane [38]. 


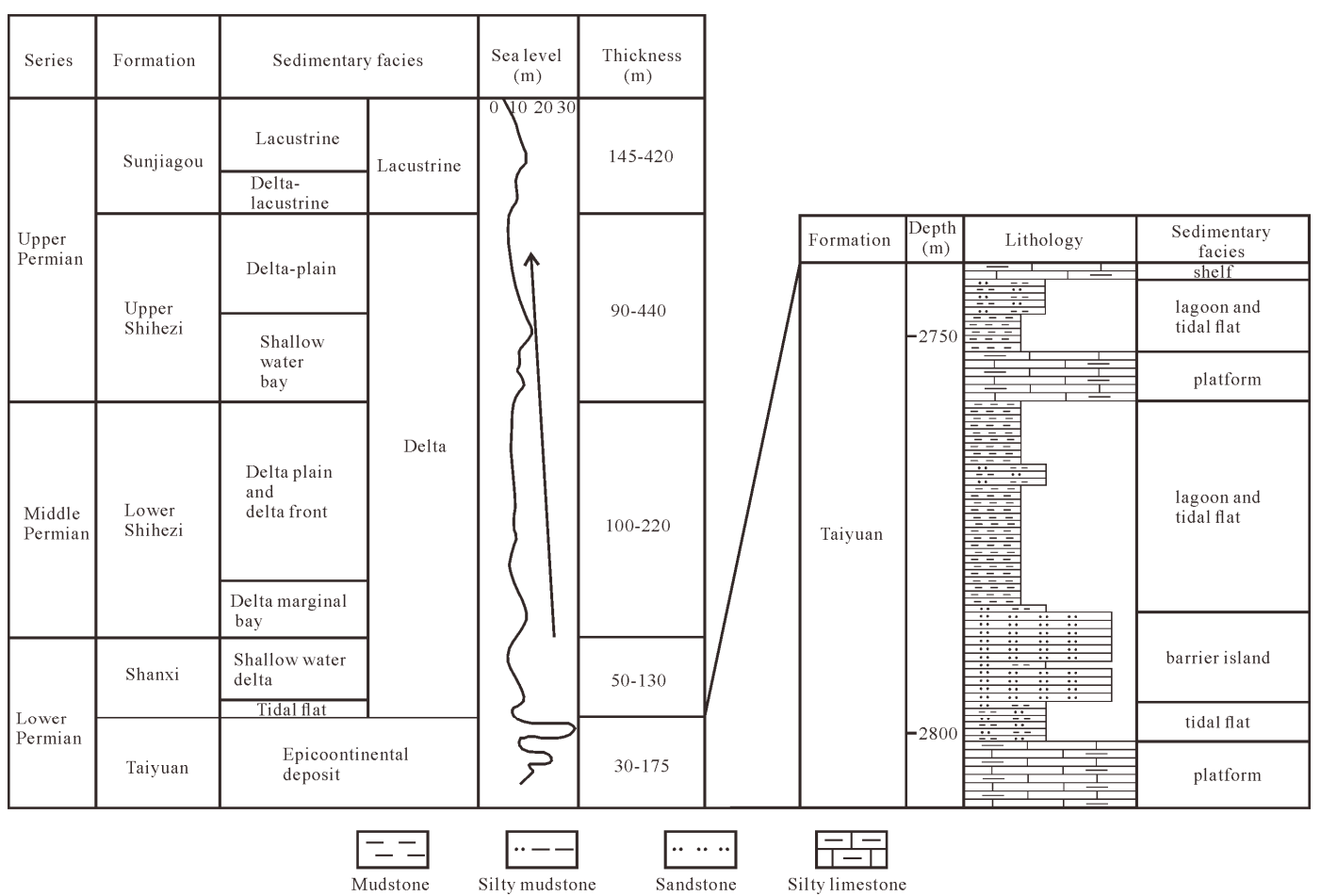

Figure 2. Map showing the stratigraphic column of Permian successions in the SNCB (modified from [38]) and more details of Taiyuan Formation (well wc1), including burial depth, lithology, sedimentary facies.

\section{Experiments and Methods}

\subsection{Samples and Experiments}

A total of 5 tight sandstone samples were selected from cores obtained in wells wc1 and wpd1 (Figure 1). Cylindrical plugs, $2.5 \mathrm{~cm}$ in diameter and 3-4 cm in length, were cut from the cores. The core plugs were carefully cleaned and dried, to remove contamination from remnant hydrocarbon and drilling fluids. The permeability of samples was first measured using a calibrated instrument DX-07G, with a steady flow of $\mathrm{N}_{2}$ based on the Chinese Core Measurement and Analysis Method Standard (GB/T29172-2012). Secondly, the samples were placed in the brine with a salinity ( 1200 mg/L), similar to formation water under vacuum for at least $24 \mathrm{~h}$, until the brine saturated state. NMR signals were generated using the brine saturated samples. The samples were put in a pulsed magnetic field, and then after a brief pulse, the NMR signal gradually decayed, with a characteristic relaxation time $\mathrm{T}_{2}$. During this process, the $T_{2}$ spectra under saturated conditions were recorded with a low-field NMR instrument Rec core 2500. Magnetic field strength and resonance frequency were $1200 \mathrm{G}$ and $2.38 \mathrm{MHz}$, respectively. Thereafter, the saturated samples were centrifuged via an HR2500-2 apparatus, to obtain an ideal irreducible water state at a rotational speed of $5000 \mathrm{r} / \mathrm{min}$. The experimental parameters were set as follows: the echo number 2048, the echo space $300 \mu \mathrm{s}$, the waiting time $6 \mathrm{~s}$, and the test temperature was $25^{\circ} \mathrm{C}$.

Subsequently, the samples were dried again, and divided into three sections, for analysis of pore structure and mineralogical compositions, respectively. Thin sections, impregnated with blue epoxy resin under vacuum, were prepared to observe the type, geometric shapes, and distribution of the pores. In the SEM experiment, the freshly broken samples, which were polished and coated with carbon in advance, were examined with a ZEISS SIGMA field emission scanning electron microscope equipped with energy-dispersive X-ray spectra (EDX), to identify clay minerals' type, the morphologies of clay occurrence within the pore spaces and micropores associated with clay minerals [39]. The mineral compositions of the samples were determined by XRD analysis, following the Oil and Gas Industry 
Standards (SY/T5463-2010). Samples were initially crushed to 100 mesh size, and then they were mixed with ethanol, ground into mortar, and placed on glass slides. The measurement was carried out using the Ultima IV X-ray diffractometer. The mineral content was quantified using Jade software.

\subsection{Theory and Methods}

\subsubsection{NMR Theory}

NMR can effectively reveal the important information about pore structure of rock, based on the $T_{2}$ transverse relaxation time [15]. The total transverse relaxation $T_{2}$ time is associated with three relaxation members: bulk relaxation $\mathrm{T}_{2 \mathrm{~B}}$, surface relaxation $\mathrm{T}_{2 \mathrm{~S}}$, and diffusion of pore fluid $\mathrm{T}_{2 \mathrm{D}}$, described as [40].

$$
\frac{1}{\mathrm{~T}_{2}}=\frac{1}{\mathrm{~T}_{2 \mathrm{~B}}}+\frac{1}{\mathrm{~T}_{2 \mathrm{~S}}}+\frac{1}{\mathrm{~T}_{2 \mathrm{D}}}
$$

Generally, the bulk relaxation and diffusion relaxation are usually ignored when magnetic field is uniform. In this case, $\mathrm{T}_{2}$ can be related directly to pore size: [16].

$$
\frac{1}{\mathrm{~T}_{2}} \approx \frac{1}{\mathrm{~T}_{2 S}}=\rho \frac{S}{V}=\rho \frac{a}{r}
$$

where $\rho(\mu \mathrm{m} / \mathrm{s})$ is the transversal surface relaxation rate; $S\left(\mu \mathrm{m}^{2}\right)$ and $V\left(\mu \mathrm{m}^{3}\right)$ are the surface area and fluid volume of pore space, respectively; the surface/volume ratio $(S / V)$ is a function of pore radius $r$ $(\mu \mathrm{m})$, and $a$ is the pore shape factor ( $a=3$ for spherical pore, while $a=2$ for tubular pore).

Thus, the $\mathrm{T}_{2}$ distribution under fully brine-saturated conditions can be converted to the curve of pore size distribution by Equation (2), with the help of $\rho$. Details of this method have been shown in the previous studies [41].

\subsubsection{Multifractal Methods Based on $\mathrm{NMR}_{2}$ Distributions}

Numerous studies have introduced the algorithm of multifractal theory in detail $[17,25,42,43]$. In this study, the popular box counting method [31] was employed for the implement of multifractal algorithm on the basis of the $100 \%$ water-saturated $\mathrm{T}_{2}$ distributions of the samples. $\mathrm{T}_{2}$ distributions are split into $N$ square boxes of size $r$, here $r=2^{m}(m=0,1,2 \ldots)$. The probability mass distribution function $P_{i}(r)$ of the $i$ th box could be represented as

$$
P_{i}(r)=\frac{M_{i}(r)}{\sum_{i=1}^{N(r)} M_{i}(r)},
$$

where $M_{i}$ is the pore volume in the ith box and $\sum_{i=1}^{N(r)} M_{i}(r)$ is the total porosity. If porosity has a multifractal distribution, and then $P_{i}(r)$ has a power exponent relationship to $r$, as follows:

$$
P_{i}(r) \propto r^{\alpha_{i}},
$$

where $\alpha_{i}$ is the singularity strength for boxes [23]. Furthermore, the number of boxes with a similar $\alpha$ value is defined as $N_{\alpha}(r)$, by the relationship:

$$
N_{\alpha}(r) \propto r^{-f(\alpha)},
$$

where $f(\alpha)$ is a multifractal or singularity spectrum, expressing the fractal dimension of boxes with similar values of $\alpha$ [19]. Furthermore, $f(\alpha)$ could reach its maximum value when the following conditions are met:

$$
\frac{\mathrm{df}(\alpha)}{d \alpha(q)}=0
$$


In order to accurately acquire the distribution properties, the partition function is expressed as:

$$
X(q, r)=\sum_{i=1}^{N(r)} P_{i}^{q}(r) \propto r^{\tau(q)},
$$

where $q$ is a moment expressing the contribution to $X(q, r)$ of boxes with diverse $P_{i}(r)$, which is commonly defined as $[-10,10]$; When $q<0, X(q, r)$ represents the density probability of the area with low concentration of porosity; when $q>0, X(q, r)$ denotes the density probability of the area with high concentration of porosity [44]. Moreover, $\tau(q)$, known as mass exponent, could be depicted by:

$$
\tau(q)=-\lim _{r \rightarrow 0} \frac{\log \sum_{i=1}^{N(r)} P_{i}^{q}(r)}{\log r},
$$

The generalized multifractal dimension $D_{q}$, another way to characterize singularity, which can be defined as:

$$
D_{q}=\frac{\tau(q)}{q-1}
$$

On the other hand, the $\alpha(q), f(\alpha)$ can also be determined from $\tau(q)$ with the Legendre transformation, respectively [43]:

$$
\begin{gathered}
\alpha(q)=\frac{d \tau(q)}{d q}, \\
f(\alpha)=q \alpha(q)-\tau(q),
\end{gathered}
$$

Generally, four sets of parameters, such as $D_{q}, \alpha(q), f(\alpha)$ and $\Delta \alpha\left(=\alpha_{\max }-\alpha_{\min }\right)$, are commonly applied to characterize pore structure heterogeneity. The more complex and nonhomogeneous pore structure corresponds to the larger value of $D_{q}$ and $\Delta \alpha$.

\section{Results}

\subsection{Mineralogical Compositions of Tight Sandstone}

The XRD analysis results of samples are shown in Table 1 . Overall, the studied $\mathrm{P}_{1} \mathrm{t}$ tight sandstone samples mainly consist of quartz and clay. Therein, quartz content ranges from $58.9 \%$ to $74.1 \%$ average as $68.42 \%$, and clay content varies from $16.3 \%$ to $35.8 \%$, with an average of $24.32 \%$. The clay minerals are dominated by the mixed illite/smectite (I/S) and illite, attended by a few kaolinites, and chlorites (Table 1). The high content of clay minerals may result from the great heterogenous composition and strong alteration of detrital feldspars in the tight sandstones [45]. There is only trace amount of feldspar $(0.9-8.3 \%$, averaging $5.22 \%)$. The lack of feldspar content is possibly due to the dissolution caused by factors such as basin subsidence, thermal events and acid produced by coal-bearing strata [46]. Other minerals, including ankerite, pyrite and calcite, can be identified only in individual samples, and their contents are extremely low $(<2.5 \%)$.

Table 1. The compositions of minerals from the $\mathrm{P}_{1} \mathrm{t}$ tight sandstone samples.

\begin{tabular}{cccccccccccc}
\hline \multirow{2}{*}{ Sample } & \multirow{2}{*}{$\begin{array}{c}\text { Depth } \\
(\mathbf{m})\end{array}$} & \multicolumn{4}{c}{ Mineralogical Composition (\%) } & \multicolumn{4}{c}{ Clay Composition (\%) } \\
\cline { 3 - 11 } & & Quartz & Feldspar & Calcite & Pyrite & Ankerite & Clay & I/S & I & K & C \\
\hline 1 & 1484.2 & 69 & 8.3 & 0.5 & 0.4 & 0 & 21.8 & 13.73 & 5.23 & 2.62 & 0.22 \\
2 & 1485.1 & 68.2 & 7.5 & 0 & 1.2 & 0 & 23.1 & 14.32 & 5.08 & 3.23 & 0.47 \\
3 & 1486.5 & 74.1 & 7.7 & 0.9 & 0 & 1 & 16.3 & 11.9 & 3.59 & 0.65 & 0.16 \\
4 & 2769.6 & 58.9 & 1.7 & 0 & 1.1 & 2.5 & 35.8 & 26.49 & 7.88 & 1.07 & 0.36 \\
5 & 2794.21 & 71.9 & 0.9 & 0 & 1.7 & 0.9 & 24.6 & 17.47 & 4.92 & 1.97 & 0.24 \\
\hline
\end{tabular}

I/S: Illite/Smectite mixed layer; I: Illite; K: Kaolinite; C: Chlorite. 


\subsection{Pore Type and Characteristics}

Casting thin section and SEM image analysis results show that there are three dominant pore types in the $\mathrm{P}_{1} \mathrm{t}$ tight sandstone samples, including micropores associated with clay minerals, secondary intergranular and intragranular dissolution pores (Figure 3). Primary intergranular pores are rarely observed. Quartz overgrowth and authigenic quartz grains are commonly developed in $\mathrm{P}_{1} \mathrm{t}$ tight sandstones (Figure 3a,b,d), and pyrite crystals are also observed in some pores (Figure 3e). Secondary dissolution pores mostly occur on detrital feldspars, as a result of partial to complete dissolution (Figure 3a,b). These dissolution pores are typically enveloped by authigenic clay minerals derived from the dissolution of detrital feldspars (Figure 3f). Additionally, a few dissolution pores occur on detrital grain boundaries (Figure 3c).
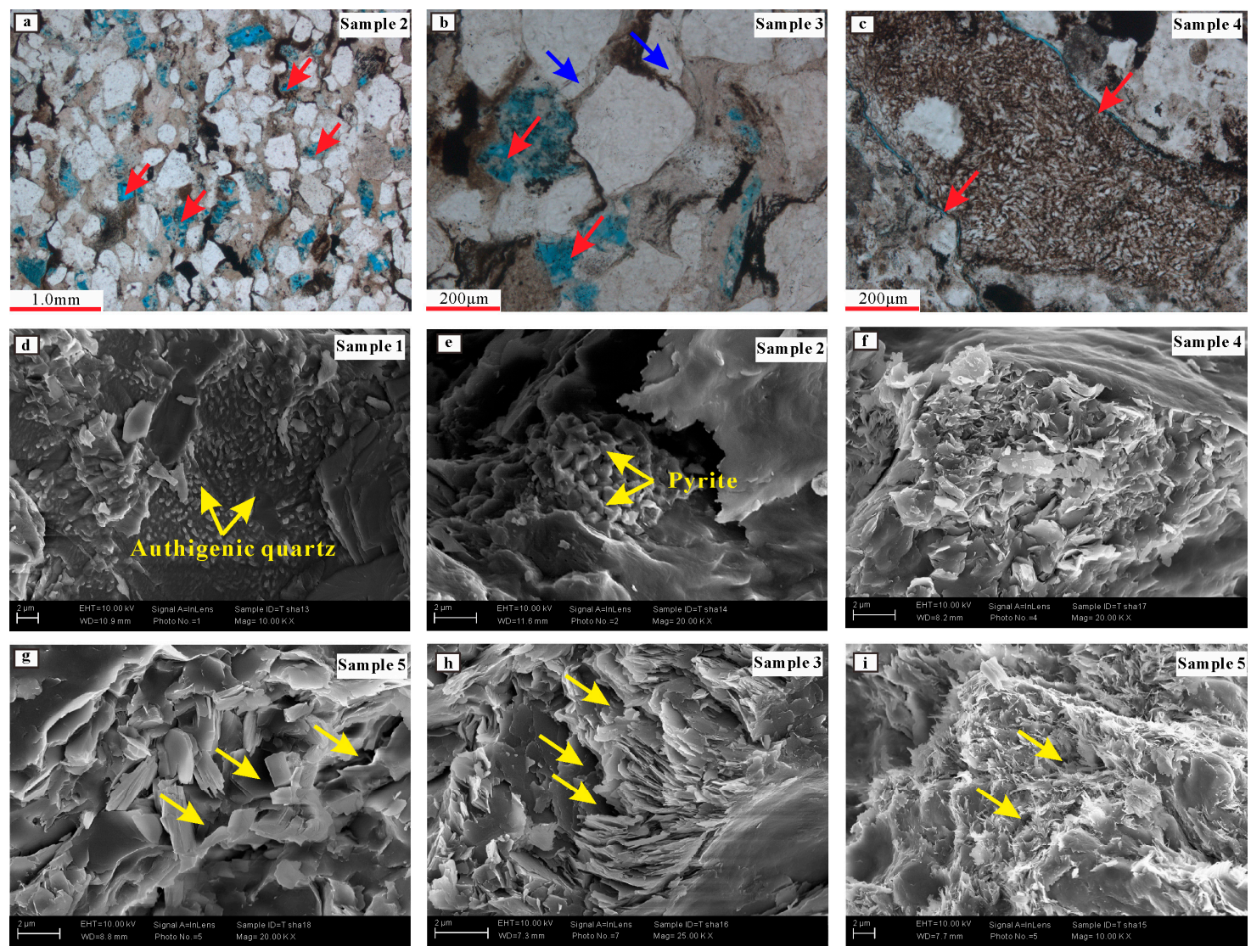

Figure 3. Photomicrographs showing the microscopic pore structure characteristics of $\mathrm{P}_{1} \mathrm{t}$ tight sandstone. (a) sandstones with intergranular and intragranular dissolution pores (red arrow) and extensive quartz overgrowths; (b) intragranular dissolution pores (red arrow) and quartz overgrowths (blue arrow); (c) dissolution pores occur on detrital grain edges (red arrow); (d) fine authigenic quartz grains; (e) pore-filling pyrites; (f) authigenic clay minerals fill the dissolution pores; (g) slablike kaolinite filling in the pore; (h) flaky illite filling in pore; (i) hair-like illite/smectite mixed layers filling in pore (yellow arrow, micropores associated with clay minerals).

The pore structures of samples are severely impacted from clay cementation, because the pore throat system is mainly filled by a large amount of authigenic clay minerals such as the slablike or booklet kaolinite (Figure 3g), and the flaky illite and hair-like mixed illite/smectite (I/S) (Figure 3h,i). SEM image analysis showed that abundant micropores are developed within these clay minerals (Figure 3g-i). These micropores are continuously distributed with a multi-scale pore size (mainly $<1 \mu \mathrm{m}$ ), which provide the necessary percolation path, connecting other relatively larger pores for tight sandstone reservoirs to a certain extent. 


\subsection{Petrophysical Properties and NMR $T_{2}$ Distributions}

The porosity of the five samples ranges from $1.95 \%$ to $3.41 \%$, with an average of $2.7 \%$, and permeability varies from $0.037 \mathrm{mD}$ to $0.494 \mathrm{mD}$ (Table 2). The petrophysical properties of samples are lower than those observed in the Chang 7 reservoir, with an average value of porosity of $7.2 \%$ and permeability of $0.18 \mathrm{mD}$. The Chang 7 reservoir is an important tight oil reservoir from Yanchang Formation in the Ordos basin [47]. This indicates that the samples have relatively poorer pore structures and reservoir quality. Nevertheless, a positive exponential relationship can be observed between porosity and permeability of samples (Figure 4).

Table 2. The petrophysical parameters and pore structure parameters of the tight sandstone samples from NMR measurements.

\begin{tabular}{ccccccccccc}
\hline \multirow{2}{*}{ Sample } & $\boldsymbol{\varphi}$ & $\mathbf{K}$ & $\boldsymbol{\varphi}_{\mathbf{m}}$ & $\boldsymbol{\varphi}_{\mathbf{b}}$ & $\mathbf{R Q I}$ & $\mathbf{F Z I}$ & $\mathbf{T}_{\mathbf{2 c u t o f f}}$ & $\mathbf{T}_{\mathbf{2 g m}}$ & $\mathbf{T}_{\mathbf{3 5}}$ & $\mathbf{T}_{\mathbf{5 0}}$ \\
\cline { 2 - 10 } & $\mathbf{( \% )}$ & $\mathbf{( m D )}$ & $\mathbf{( \% )}$ & $\mathbf{( \% )}$ & $\mathbf{( \mu \mathbf { m } )}$ & $\mathbf{( \mu \mathbf { m } )}$ & $\mathbf{( m s )}$ & $\mathbf{( m s )}$ & $\mathbf{( m s )}$ & $(\mathbf{m s})$ \\
\hline 1 & 2.63 & 0.044 & 0.38 & 2.25 & 0.041 & 0.151 & 3.5 & 1.93 & 1.42 & 1.86 \\
2 & 2.98 & 0.064 & 1.5 & 1.48 & 0.046 & 0.149 & 2.08 & 2.7 & 1.46 & 2.04 \\
3 & 1.95 & 0.037 & 0.67 & 1.28 & 0.044 & 0.219 & 2.45 & 2.37 & 1.18 & 1.5 \\
4 & 2.53 & 0.134 & 1.45 & 1.08 & 0.073 & 0.280 & 1.4 & 1.73 & 1.28 & 1.7 \\
5 & 3.41 & 0.494 & 1.85 & 1.56 & 0.12 & 0.341 & 1.86 & 2.67 & 1.48 & 2.1 \\
\hline
\end{tabular}

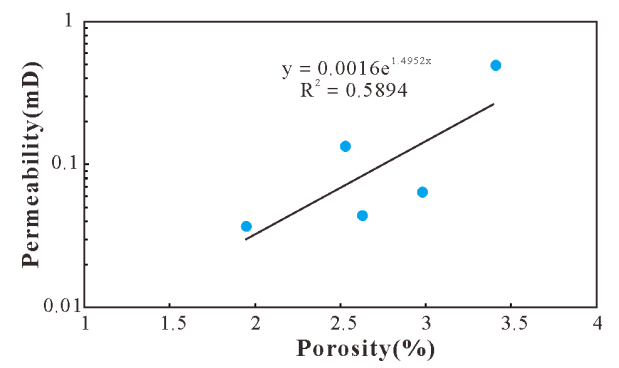

Figure 4. The correlation between porosity and permeability of $\mathrm{P}_{1} \mathrm{t}$ sandstone.

Reservoir quality index (RQI) and flow zone indicator (FZI) are two ideal macroscopic petrophysical parameters used to evaluate the micro pore structure and reservoir properties of tight sandstone [48]. RQI and FZI were calculated by the following formulas, respectively [33]:

$$
\begin{aligned}
& \mathrm{RQI}=0.0316 \times \sqrt{\frac{\mathrm{K}}{\varphi}}, \\
& \mathrm{FZI}=\mathrm{RQI} \times \frac{100-\varphi}{\varphi},
\end{aligned}
$$

where $\mathrm{K}$ is the permeability, $\mathrm{mD} ; \varphi$ is the porosity, $\%$.

As shown in Table 2, the values of RQI vary from $0.0041 \mu \mathrm{m}$ to $0.012 \mu \mathrm{m}$, while FZI values range from $0.1498 \mu \mathrm{m}$ to $0.341 \mu \mathrm{m}$, averaging as $0.228 \mu \mathrm{m}$. These values are close to the tight oil reservoir researched by Zhao et al., 2017, whereas they are lower than the Chang 7 tight reservoir [47].

For the fully water-saturated rock, the $\mathrm{T}_{2}$ distributions provide information about the pore size distributions. The $T_{2}$ relaxation time is in proportion to the pore size $[15,49]$, and the signal amplitude of $\mathrm{T}_{2}$ distributions reflect the pore fluid content and pore volume. The $100 \%$ brine-saturated $\mathrm{T}_{2}$ spectra of five samples are shown in Figure 5. Except for sample 1 (unimodal $\mathrm{T}_{2}$ spectrum), all samples show the bimodal characteristics of $\mathrm{T}_{2}$ spectra, and almost all pore sizes of tight sandstones present in the range from 0.1 to $100 \mathrm{~ms}$. There are no pores with the relaxation time larger than $100 \mathrm{~ms}$, attributed to the absence of residually large intergranular pores. The main peaks are distributed between $0.1 \mathrm{~ms}$ and $10 \mathrm{~ms}$, and their signal amplitudes are far larger than the secondary peak. The relative amplitudes 
of $\mathrm{T}_{2}$ peaks indicate that sample porosities are dominated by smaller pore sizes, and the larger porosity are relatively few. The pores of sample 1 are all smaller pores.

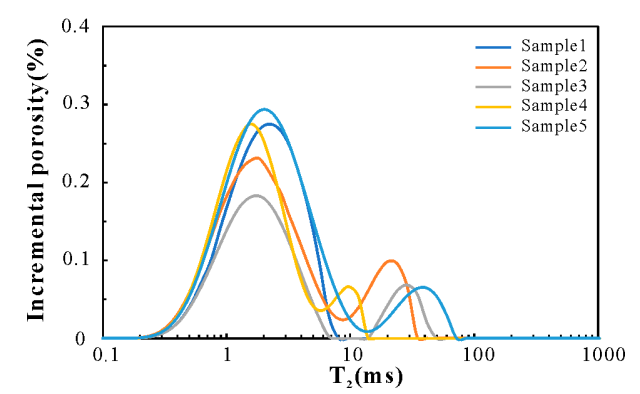

Figure 5. The saturated NMR $\mathrm{T}_{2}$ spectra of samples.

By analyzing NMR $T_{2}$ data, some NMR pore structure parameters, including movable-fluid porosity $\left(\varphi_{\mathrm{m}}\right)$, bound-fluid porosity $\left(\varphi_{\mathrm{b}}\right), \mathrm{T}_{2 \text { cutoff, }} \mathrm{T}_{2 \mathrm{gm}}$ (amplitude weighted logarithmic mean), $\mathrm{T}_{35}$ and $\mathrm{T}_{50}$, are also summarized in Table 2 . Porosity in the rock can be separated into bound-fluid porosity ( $T_{2}<T_{2 \text { cutoff }}$ ) and movable-fluid porosity ( $T_{2}>T_{2 \text { cutoff }}$ ) in the cumulative $T_{2}$ spectrum by $\mathrm{T}_{2 \text { cutoff }}$ value (Figure 6 ). The bound-fluid porosity of tight sandstone usually exists in clay-dominated micropores, which contain capillary and clay-bound water, while movable-fluid porosity tends to reside in large pores which are connected by effective pore throat [18]. Then, the movable-fluid porosity is determined by removing the proportion of the bound fluid from the $100 \%$ brine-saturated NMR signal, varying from $0.38 \%$ to $1.85 \%$. Compared to movable-fluid porosity, bound-fluid porosity is commonly high, with the range of $1.08 \%-2.25 \%$, indicating that the sandstone samples have the complex pore structure with poor pore connectivity. $T_{35}, T_{50}$ are corresponding to the $T_{2}$ value, where the samples reach $35 \%$ and $50 \%$ brine saturation in the cumulative $\mathrm{T}_{2}$ distributions, respectively [3]. Overall, compared to Chang 7 and Xujiahe tight sandstone reservoirs [48,50], $\mathrm{T}_{2 \text { cutoff, }} \mathrm{T}_{21 \mathrm{~m}}, \mathrm{~T}_{35}$, and $\mathrm{T}_{50}$ of samples are characterized by relatively lower values, indicating a narrower pore size distribution in the samples.

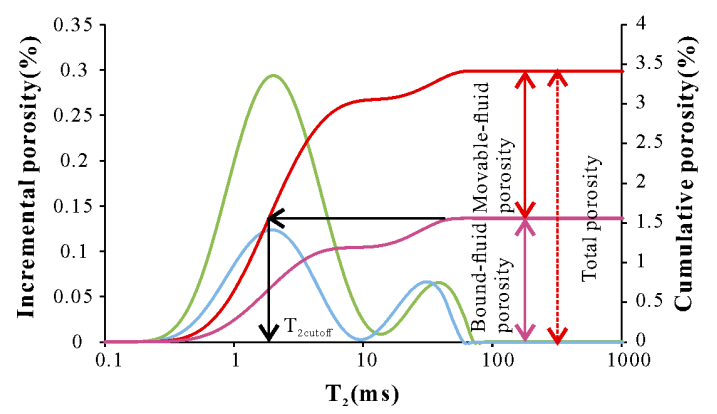

Figure 6. The cumulative and incremental $\mathrm{T}_{2}$ spectrum of sample 5.

\subsection{Multifractal Characteristics}

In this study, multifractal characteristics of pore structures were obtained from $100 \%$ brine-saturated $\mathrm{T}_{2}$ spectra. The range of moments $q$ is defined in the interval from -10 to 10 . The generalize dimension spectra $\left(D_{q} \sim q\right)$ and the relationship of mass exponent $\tau(q)$ versus $q$ are presented in Figures 7 and 8 , respectively. The $D_{q}$ with respect to variable $q$ shows an inverse S-shaped curve. $D_{q}$ has a larger variation for $q<0$, while a minor variation for $q>0$. Moreover, $\tau(q)$ follows a monotone increase as $q$ increase, and the increasing trend gradually becomes smoother with increasing $q$. Figure 9 represents the multifractal spectra or singularity spectra of samples, where $\alpha(q)$ are also strongly correlated to the variable $q$. Overall, these spectra of different samples all show two different variation trends, that reveal that the pore size distributions of tight sandstone samples are multifractal. Therefore, the heterogeneity 
of pore volume distribution can be represented via the generalized dimension and singularity spectra shape and its characteristic parameters, which further reveal the local differences in the whole.

Generally, the heterogeneity of the whole pore size distribution is assessed by the total width of singularity spectra $\alpha_{-10}-\alpha_{10}$ and generalized dimension spectra $D_{-10}-D_{10}$ [19]. Higher values of $\alpha_{-10}-\alpha_{10}$ and $D_{-10}-D_{10}$ usually suggest a more heterogeneous pore size distribution within samples, and vice versa. The right part of the generalized dimension spectra and the singular spectra $(q>0)$ corresponds to the areas with higher probability density of porosity distribution (concentrated areas). However, the left part of the generalized dimension spectra and the singular spectra $(q<0)$ represent the areas with lower probability density (sparse areas) [32,51]. Therefore, multifractality parameters $D_{10}, D_{0}-D_{10}, \alpha_{10}$, and $\alpha_{0-} \alpha_{10}$ can describe the pore characteristics in higher probability areas, and the parameters $D_{-10}, D_{-10}-D_{0}, \alpha_{-10}$, and $\alpha_{-10}-\alpha_{0}$ play the same role in lower probability areas. For the studied sandstone samples, the porosities in higher probability density areas mainly consist of the smaller pores, such as clay-dominated micropores, whereas the porosities in lower probability density areas mainly refer to the larger pores, such as intergranular dissolution pores, with a relatively larger pore size.

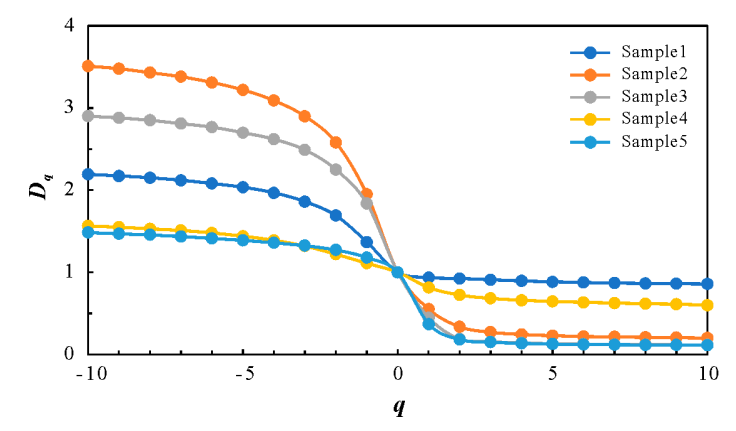

Figure 7. Generalized multifractal dimension spectra.

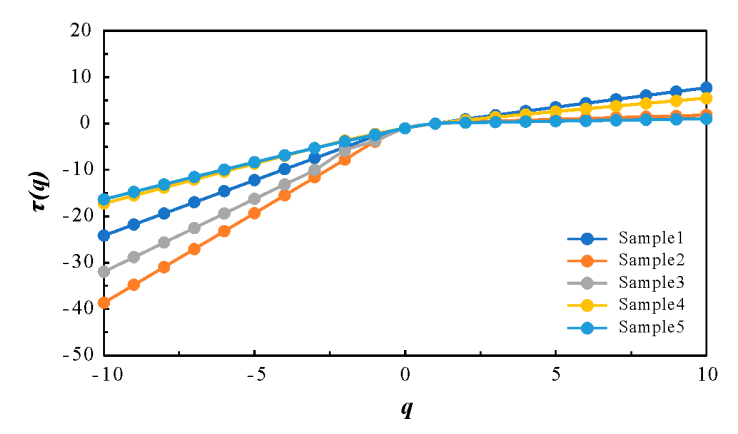

Figure 8. Generalized mass exponent $\tau(q)$ versus variable $q$.

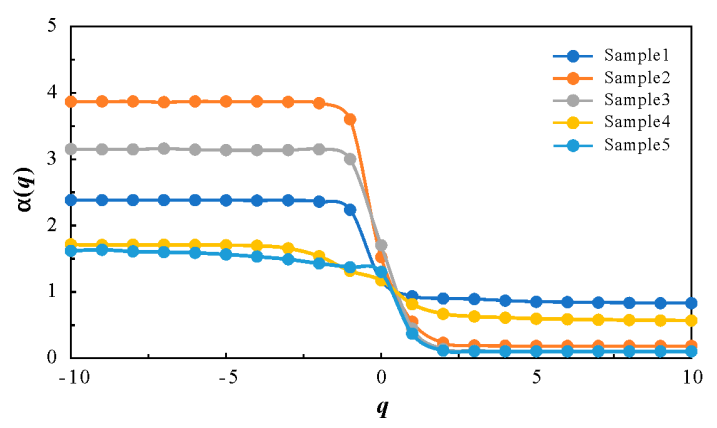

Figure 9. Multifractal spectra of five samples.

$D_{0}$ is defined as a capacity dimension or box-counting dimension. $D_{1}$, as an information dimension, is a measure of concentration degree of pore size distribution [28]. $D_{2}$ is the correlation dimension, 
which explains the scaling behavior of the second sampling moments [25]. For a monofractal structure, $D_{0}=D_{1}=D_{2}$ [44]. However, as shown in Table 3, all samples show a same order of $D_{0}>D_{1}>D_{2}$, suggesting that the pore size distribution of every studied tight sandstone sample has a tendency toward a multifractal type of scaling. Additionally, the calculated $D_{-10}, D_{10}, D_{-10}-D_{0}, D_{0}-D_{10}$ and $D_{-10}-D_{10}$ are also listed in Table 3. For all samples, $D_{-10}>D_{10}$ and $D_{-10}-D_{0}>D_{0}-D_{10}$, indicating that the pore distributions of higher probability areas may be more homogeneous than that of lower probability areas.

Table 3. The generalized dimensions of samples.

\begin{tabular}{ccccccccc}
\hline Sample & $\boldsymbol{D}_{-\mathbf{1 0}}$ & $\boldsymbol{D}_{\mathbf{0}}$ & $\boldsymbol{D}_{\mathbf{1}}$ & $\boldsymbol{D}_{\mathbf{2}}$ & $\boldsymbol{D}_{\mathbf{1 0}}$ & $\boldsymbol{D}_{-\mathbf{1 0}}-\boldsymbol{D}_{\mathbf{0}}$ & $\boldsymbol{D}_{\mathbf{0}}-\boldsymbol{D}_{\mathbf{1 0}}$ & $\boldsymbol{D}_{-\mathbf{1 0}}-\boldsymbol{D}_{\mathbf{1 0}}$ \\
\hline 1 & 2.19 & 1 & 0.95 & 0.94 & 0.86 & 1.19 & 0.142 & 1.33 \\
2 & 3.5 & 1 & 0.55 & 0.34 & 0.2 & 2.5 & 0.8 & 3.3 \\
3 & 2.9 & 1 & 0.45 & 0.188 & 0.12 & 1.9 & 0.88 & 2.78 \\
4 & 1.57 & 1 & 0.82 & 0.72 & 0.6 & 0.57 & 0.4 & 0.97 \\
5 & 1.49 & 1 & 0.37 & 0.18 & 0.11 & 0.49 & 0.89 & 1.38 \\
\hline
\end{tabular}

For singularity parameters, the similar trend, $\alpha_{-10}>\alpha_{10}$ and $\alpha_{-10}-\alpha_{0}>\alpha_{0}-\alpha_{10}$, are also found in Table 4, indicating that the pore system in lower probability density areas owns more obvious multifractal characteristics than that in a higher probability density area. As presented in Table 4, the values of $\alpha_{10}-\alpha_{-10}$ are in the range of 1.15-3.69, indicating that the pore structures of samples are highly heterogeneous. The parameter $A=\left(\alpha_{0}-\alpha_{10}\right) /\left(\alpha_{-10}-\alpha_{0}\right)$ is referred to express the asymmetry of singularity spectrum, and $A>1$ demonstrates a strong fluctuation in pore size distribution. The values of A for sample 1 and sample 2 are lower than 1, which exhibit more stable pore size distributions compared to those of other samples. The multifractal analysis of tight sandstone pores shows that the pore distribution is complicated, multifractal and heterogeneous.

Table 4. The singularity parameters of samples.

\begin{tabular}{cccccccc}
\hline Sample & $\boldsymbol{\alpha}_{-\mathbf{1 0}}$ & $\boldsymbol{\alpha}_{\mathbf{1 0}}$ & $\boldsymbol{\alpha}_{\mathbf{0}}$ & $\boldsymbol{\alpha}_{\mathbf{1 0}}-\boldsymbol{\alpha}_{\mathbf{0}}$ & $\boldsymbol{\alpha}_{\mathbf{0}}-\boldsymbol{\alpha}_{-\mathbf{1 0}}$ & $\boldsymbol{\alpha}_{\mathbf{1 0}}-\boldsymbol{\alpha}_{-\mathbf{1 0}}$ & $\boldsymbol{A}$ \\
\hline 1 & 2.38 & 0.83 & 1.17 & 1.21 & 0.34 & 1.55 & 0.12 \\
2 & 3.87 & 0.18 & 1.52 & 2.35 & 1.34 & 3.69 & 0.57 \\
3 & 3.15 & 0.1 & 1.7 & 1.45 & 1.6 & 3.05 & 1.1 \\
4 & 1.71 & 0.57 & 1.17 & 0.54 & 0.6 & 1.14 & 1.12 \\
5 & 1.62 & 0.1 & 1.3 & 0.32 & 1.2 & 1.52 & 3.74 \\
\hline
\end{tabular}

\section{Discussion}

The results shown in the preceding section manifest that several multifractal parameters can be utilized to characterize the pore heterogeneity. In this study, only two multifractal parameters $\left(D_{10}\right.$ and $D_{-10}$ ) are selected to describe multifractal characteristics and evaluate pore heterogeneity in different probability measure areas within tight sandstones. The multifractal parameter $D_{10}$ are used to account for multifractal behaviors of pore network in higher probability density areas, while the parameter $D_{-10}$ represents the multifractal characteristics of pore network in lower probability density areas.

\subsection{Relationship between Petrophysical Parameters of Tight Sandstone and Multifractal Parameters}

Petrophysical property is the most direct performance of the pore structure of tight sandstone which can significantly affect fractal characteristics of pores. Figure 10 illustrates that multifractal parameters $\left(D_{10}\right.$ and $\left.D_{-10}\right)$ show a negative correlation with permeability, RQI and FZI, but they have no obvious relationship with porosity. Theoretically, porosity is mainly affected by the content of pore in the rock, especially large pore, which is independent of the complexity of pore distribution. Nevertheless, multifractal parameters mainly reflect the irregularity and complexity of pore geometry and pore network, with a significant influence on permeability, RQI and FZI. Meanwhile, not all pores 
are suitable for fractal analysis, and fractal analysis from a NMR $\mathrm{T}_{2}$ spectrum only focus on pores with the pore size larger than dozens of nanometers or hundreds of nanometers [7], because the relaxation mechanism of fluid is quite complex in the smaller pore. In this case, the influence of bulk relaxation and diffusion relaxation should be considered, and $\mathrm{T}_{2}$ cannot be directly simplified to surface relaxation $\mathrm{T}_{2 \mathrm{~s}}$. Therefore, the porosity of samples as a quantity cannot effectively constrain the heterogeneity of the pore structure [29].

Besides, $D_{-10}$ shows a more sensitive response to permeability, RQI and FZI than $D_{10}$, indicating that pore structure in lower probability density areas has a significant impact on petrophysical properties of tight sandstone reservoirs. From the $\mathrm{T}_{2}$ distributions and petrographic observations of sandstone samples, small-scale clay-dominated micropores associated with short $\mathrm{T}_{2}$ components $\left(\mathrm{T}_{2}<10 \mathrm{~ms}\right.$ ) constitute the majority of the pore system, and only a few proportions are composed of the large-scale dissolution pores associated with long $T_{2}$ components $\left(T_{2}>10 \mathrm{~ms}\right)$. Hence, pore system in lower probability density areas mainly consists of dissolution pores with low content; micropores dominate pore system in higher probability density areas. The formation of dissolution pores with larger pore scale, however, greatly improve reservoir properties. Therefore, the complexity of pore system composed of dissolution pores play a more important role in the petrophysical properties of sandstones.

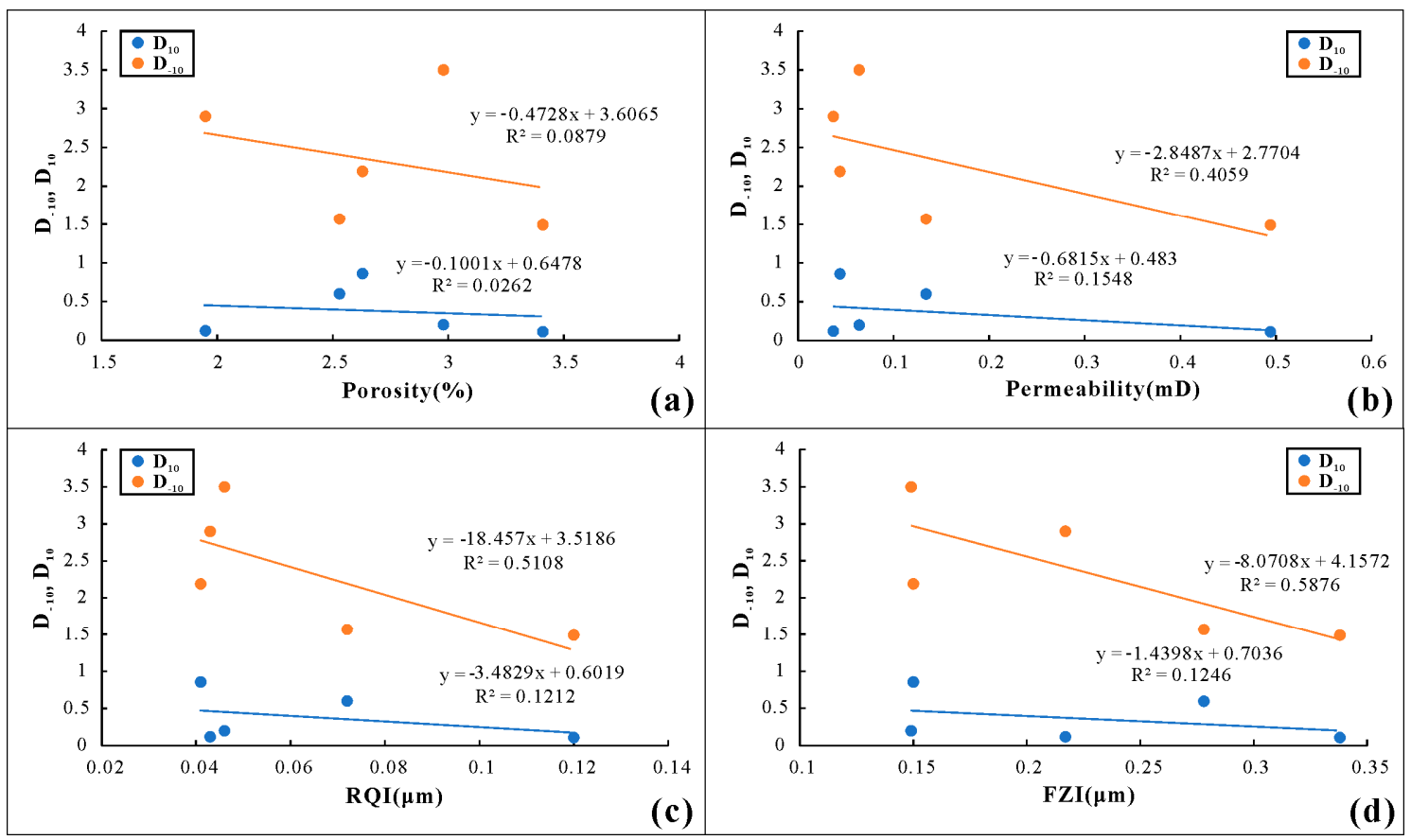

Figure 10. The correlations between petrophysical parameters with multifractal parameters. (a) the correlations between $D_{-10}, D_{10}$ with porosity; (b) the correlations between $D_{-10}, D_{10}$ with permeability; (c) the correlations between $D_{-10}, D_{10}$ with RQI; (d) the correlations between $D_{-10}, D_{10}$ with FZI.

Furthermore, the correlation coefficients of multifractal parameters with permeability, RQI and FZI show an increasing trend (Figure 10). This can be explained by the fact that RQI and FZI integrate porosity and permeability, which is the better petrophysical parameters for characterizing the pore structure of tight sandstone. Meanwhile, FZI is the combination of several microscopic pore structure properties, e.g., pore specific surface area, morphology and tortuosity, and therefore the highest correlation coefficient [33]. Hence, FZI is a superior indicator of the pore structure heterogeneity of tight sandstone, especially in the lower probability density area. 


\subsection{Relationship between Pore Structure of Tight Sandstone and Multifractal Parameters}

The relationships between multifractal parameters and NMR pore structure parameters of tight sandstone, including movable-fluid porosity $\left(\varphi_{\mathbf{m}}\right)$, bound-fluid porosity $\left(\varphi_{\mathbf{b}}\right), \mathrm{T}_{2 \text { cutoff, }}, \mathrm{T}_{2 \mathrm{gm}}, \mathrm{T}_{35}$ and $\mathrm{T}_{50}$, are also analyzed, and the correlation coefficients are summarized in Table 5. $D_{10}$ is highly associated with movable-fluid porosity, bound-fluid porosity, $\mathrm{T}_{2 \text { cutoff }}$ and $\mathrm{T}_{2 \mathrm{gm}}$, but it has no apparent correlation with $\mathrm{T}_{35}$ and $\mathrm{T}_{50}$ (Figure 11). Additionally, $D_{-10}$ shows few or no relationships with pore structure parameters (Table 5). This may be because small-scale micropores in higher probability density areas dominate the entire pore system of tight sandstone reservoirs, and thus, multifractal parameters of higher probability density regions are more useful for pore structure characterization of tight sandstone.

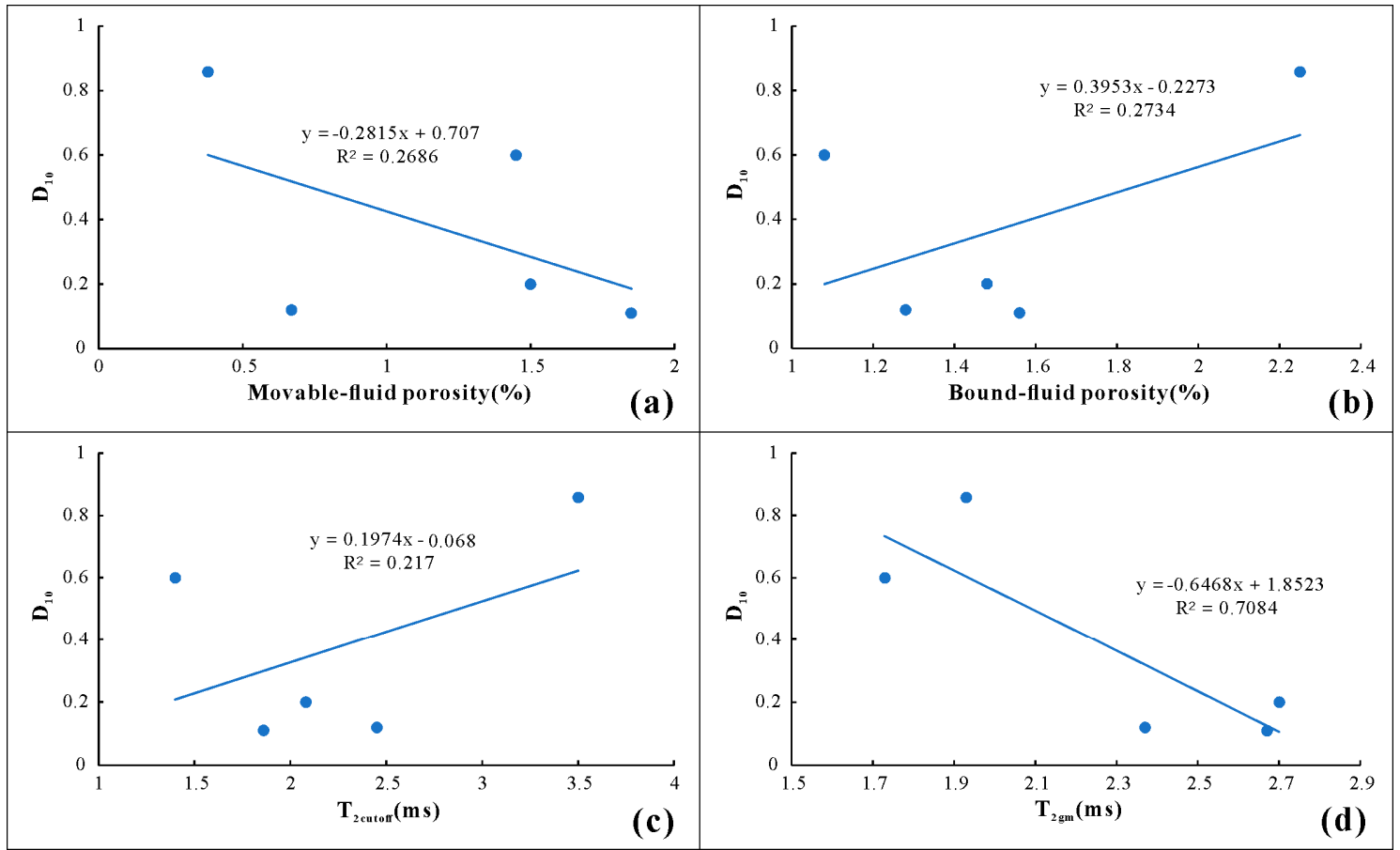

Figure 11. The correlations between multifractal parameter $D_{10}$ and NMR pore structure parameters. (a) the correlation between $D_{10}$ with movable-fluid porosity; (b) the correlation between $D_{10}$ with bound-fluid porosity; (c) the correlation between $D_{10}$ with $\mathrm{T}_{2 \text { cutoff }}$ (d) the correlation between $D_{10}$ with $\mathrm{T}_{2 \mathrm{gm}}$.

The $T_{2 \text { cutoff }}$ is the efficient boundary which divides the total pore volume into movable-fluid pores and bound-fluid pores, according to whether the fluid within them can flow or not. For the studied sandstone samples, immovable bound-fluid mainly exists in clay-dominated micropores with poor connectivity, while movable fluid tends to exist in those dissolution pores which are connected by effective pore throats. $T_{2 \text { cutoff }}$ value severely affects the proportion of different type of pores in tight sandstones. The larger the $T_{2 \text { cutoff }}$ value, the more bound-fluid pores, and the fewer movable-fluid pores (Figure 12), which increase the heterogeneity of pore network in higher probability density areas. 


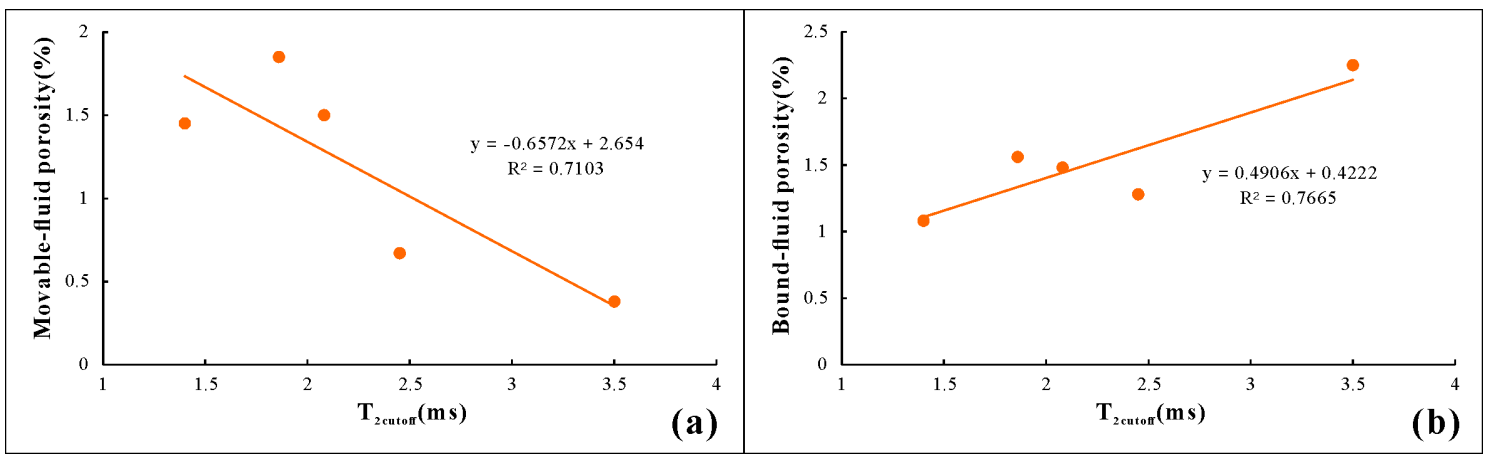

Figure 12. The correlations between movable-fluid porosity, bound-fluid porosity and $\mathrm{T}_{2 \text { cutoff. }}$ (a) the correlation between $\mathrm{T}_{2 \text { cutoff }}$ with movable-fluid porosity; $(\mathbf{b})$ the correlation between $\mathrm{T}_{2 \text { cutoff }}$ with bound-fluid porosity.

Figure 11d illustrates that $T_{2 g m}$ has the negative correlation with $D_{10}$. The $T_{2 g m}$ is a comprehensive performance for the whole pore size distribution of rock, and the large $T_{2 g m}$ value means a good pore structure in the tight sandstone reservoirs [52]. In this study, a large amount of short $\mathrm{T}_{2}$ components related to micropores not only dominate the whole $T_{2}$ distributions of sandstone samples, but also constitute the main peak. Therefore, $\mathrm{T}_{2 \mathrm{gm}}$ mainly reflects the characteristics of main peak corresponding to pore system in higher probability density areas. Therefore, the heterogeneity of pore network of the high probability density areas tends to decrease as $\mathrm{T}_{2 \mathrm{gm}}$ increases.

Table 5. The correlation coefficients between multifractal parameters and pore structure parameters.

\begin{tabular}{ccccccc}
\hline & $\boldsymbol{\varphi}_{\mathbf{m}}(\mathbf{\%})$ & $\boldsymbol{\varphi}_{\mathbf{b}}(\mathbf{\%})$ & $\mathbf{T}_{\mathbf{2 c u t o f f}}(\mathbf{m s})$ & $\mathbf{T}_{\mathbf{2 g m}}(\mathbf{m s})$ & $\mathbf{T}_{\mathbf{3 5}}(\mathbf{m s})$ & $\mathbf{T}_{\mathbf{5 0}}(\mathbf{m s})$ \\
\hline $\mathrm{D}_{10}$ & -0.2686 & 0.2734 & 0.217 & -0.7084 & 0.0019 & -0.0139 \\
$\mathrm{D}_{-10}$ & -0.0717 & 0.0001 & 0.0678 & 0.2039 & -0.0058 & -0.0076 \\
\hline
\end{tabular}

\subsection{Effect of miNeral Compositions of Tight Sandstone on Multifractal Characteristics}

Several studies have testified that mineral compositions, mineral content and contact between minerals have a significant impact on the pore structure of rock, and the influence of each mineral on pores in distinct lithology may also be different $[5,8,30,45,53]$.

As shown in Figure 13a, quartz content shows the negative correlation with $D_{10}$ and the weak negative relationship with $D_{-10}$. This result demonstrates that quartz plays different roles in the pore structure of different probability density areas. Sandstone petrographic observations show that the studied tight sandstone samples mainly consist of sedimentary quartz grains (Figure 3a,b), which act as the main skeleton minerals of the tight sandstone to resist compaction for the preservation of pores. In general, the higher content of quartz contributes to the higher textural maturity of sandstone and regular pore structure, which decrease the complexity of the pore systems in higher probability density areas. Nevertheless, the tight sandstone samples contain some authigenic quartz grains filling parts of large dissolution pores, which lead to the irregular pore geometry in lower probability density areas and thus larger values of $D_{-10}$.

According to Figure 13b, feldspar content is well correlated to $D_{-10}$, but has no correlation with $D_{10}$. The above relationships indicate that tight sandstone with high feldspar content tends to have relatively complex and anisotropic pore structure in lower probability density areas. The content of feldspar in tight sandstone is associated with the diagenesis process. After deposition, the Taiyuan Formation experienced a long period of deep burial and diagenetic processes, and the chemical environment of fluid changed since a large amount of organic acids and $\mathrm{CO}_{2}$ were generated during the early hydrocarbon generation of the organic matter in the source rock, which causes the extensive dissolution of chemically unstable aluminosilicates, such as feldspar. In this study, feldspar contents of all samples are low (average 5.22\%), and secondary dissolution porosities as a result of partial/complete 
dissolution of feldspars are well observed in the sandstone samples (Figure 3a,b), indicating that feldspar experienced the strong alteration. These dissolution pores provide extra pore space for gas storage, while feldspar dissolution is always accompanied by by-products (e.g., authigenic quartz, kaolinite, illite) which precipitate in situ or in adjacent pores, resulting in a rather complex pore network in lower probability density areas.

Different from quartz and feldspar, clay content shows the weak positive correlation with $D_{10}$, whereas it has a better negative relationship with $D_{-10}$ (Figure 13c). This finding indicates that the effect of clay minerals on the pore structure in different probability density areas is rather complex. A high content of clay can not only reduce complexity of pore in lower probability density areas, but also increases the pore heterogeneity of higher probability density areas. This may be interpreted that tight sandstone samples have the high clay content (average $24.32 \%$ ), and micropores associated with clay minerals predominate the pore system of the high probability measure areas. The SEM image analysis results show that a large amount of clay minerals fill in between quartz grains with slablike, flaky, and hair-like forms (Figure 3g-i), blocking the pore throat system, causing some large pores to be closed and semi-closed. The micropores gradually replace the large pores, and reduce the amounts of large pores with increasing clay content, which decreases the complexity of the pore network of lower probability density areas. However, clay-dominated micropores have different characteristics within various types of clay minerals, which are also characterized by multi-type pores with multi-scale pore size ranging from nanoscale to microscale, such as intracrystalline micropores (mainly $<2 \mathrm{~nm}$ ), within aluminosilicate layers, inter-crystalline micropores (2-50 $\mathrm{nm}$ ) between clay particles, and interparticle micropores $(>0 \mathrm{~nm})$ between aggregated clay particles [54]. These factors complicate the pore network in higher probability density areas, resulting in higher $D_{10}$.

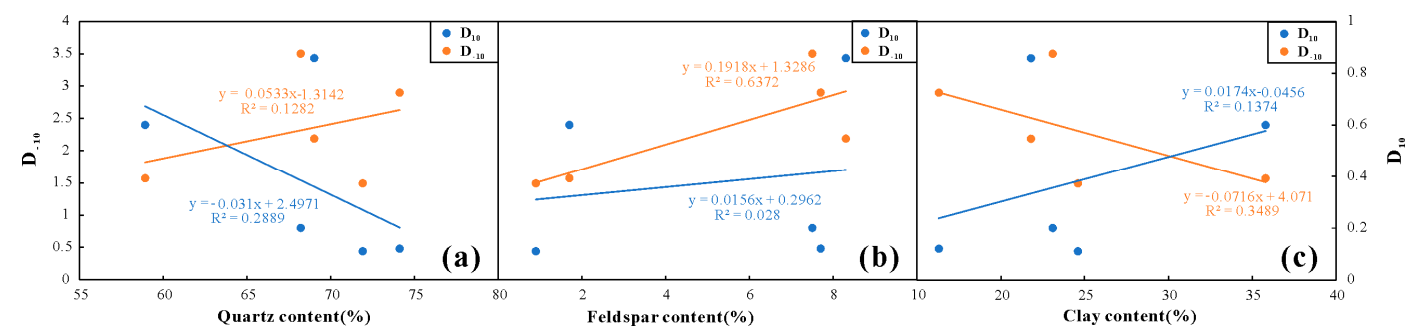

Figure 13. The correlations between mineral compositions and multifractal parameters. (a) the correlations between $D_{-10}, D_{10}$ with quartz content; (b) the correlations between $D_{-10}$, $D_{10}$ with feldspar content; (c) the correlations between $D_{-10}, D_{10}$ with clay content.

\section{Conclusions}

In the presented research, the pore structure and its heterogeneity of the Lower Permian Taiyuan Formation tight sandstone in the south China North basin were investigated by a series of experiments and multifractal methods. These conclusions could be obtained:

(1) The tight sandstones from Taiyuan Formation are characterized by a high content of quartz and clay minerals, low porosity $(1.95-3.41 \%)$ and low permeability $(0.037-0.494 \mathrm{mD})$. Pore types mainly include micropores associated with clay minerals, intergranular and intragranular dissolution pores, whereas primary pores are rarely observed. The $\mathrm{NMR} \mathrm{T}_{2}$ distributions of samples mainly show bimodal characteristics with less long $\mathrm{T}_{2}$ components, since clay-dominated micropores associated with short $\mathrm{T}_{2}$ components predominate the whole pore system of the tight sandstones.

(2) The multifractal spectrum, generalized dimensions and mass exponent spectrum demonstrate that pore structures of tight sandstone samples have multifractal characteristics. Meanwhile, the multifractal parameters are useful to quantify the pore heterogeneity in the areas with different probability densities. 
(3) Multifractal parameter $\left(D_{-10}\right)$ of lower probability density areas is more appropriate to determine petrophysical properties. However, the multifractal parameter $\left(D_{10}\right)$ of higher probability density areas is the available indicators for evaluating pore structure.

(4) Mineral compositions have various effects on pore structure in different probability density areas. The decrease of quartz content and increase in clay mineral content contribute to high degree of pore anisotropy of higher probability density areas, whereas the decrease in clay minerals and the increase of quartz content and feldspar content can result in more irregular and nonhomogeneous pore network in lower probability density areas.

(5) Overall, the pore structure in lower probability density areas consists of larger dissolution pores, which determine the reservoir properties. Gas storage and seepage usually occur at those pores of lower probability density areas. However, micropores dominate pore structure in higher probability density areas, and strong complexity and heterogeneity make pores unfavorable for gas storage and seepage there.

Author Contributions: K.Q. conceived of the presented idea, designed the experiments and verified the data along with S.G. The article is originally written by K.Q. and revised by the corresponding author S.G. All authors have read and agreed to the published version of the manuscript.

Funding: This work was funded by Ministry of Science and Technology of the People's Republic of China (Grant No. 2016ZX05034).

Acknowledgments: This study received financial support from the Ministry of Science and Technology of the People's Republic of China (Grant No. 2016ZX05034). We would like to thank the anonymous reviewers for their careful reviews and detailed suggestions.

Conflicts of Interest: The authors declare no conflicts of interest.

\section{References}

1. Desbois, G.; Urai, J.L.; Kukla, P.A.; Konstanty, J.; Baerle, C. High-Resolution 3D fabric and porosity model in a tight gas sandstone reservoir: A new approach to investigate microstructures from $\mathrm{mm}$ - to nm-scale combining argon beam cross-sectioning and SEM imaging. J. Pet. Sci. Eng. 2011, 78, 243-257. [CrossRef]

2. Zou, C.; Zhu, R.; Liu, K.; Su, L.; Bai, B.; Zhang, X.; Yuan, X.; Wang, J. Tight gas sandstone reservoirs in China: Characteristics and recognition criteria. J. Pet. Sci. Eng. 2012, 88-89, 82-91. [CrossRef]

3. Rezaee, R.; Saeedi, A.; Clennell, B. Tight gas sands permeability estimation from mercury injection capillary pressure and nuclear magnetic resonance data. J. Pet. Sci. Eng. 2012, 88-89, 92-99. [CrossRef]

4. Zhang, L.; Lu, S.; Xiao, D.; Li, B. Pore structure characteristics of tight sandstones in the northern Songliao Basin, China. Mar. Pet. Geol. 2017, 88, 170-180. [CrossRef]

5. Loucks, R.G.; Reed, R.M.; Ruppel, S.C.; Hammes, U. Spectrum of pore types and networks in mudrocks and a descriptive classification for matrix-related mudrock pores. AAPG Bull. 2012, 96, 1071-1098. [CrossRef]

6. Xi, K.; Cao, Y.; Haile, B.G.; Zhu, R.; Jahren, J.; Bjørlykke, K.; Zhang, X.; Hellevang, H. How does the pore-throat size control the reservoir quality and oiliness of tight sandstones? The case of the lower cretaceous quantou formation in the southern Songliao Basin, China. Mar. Pet. Geol. 2016, 76, 1-15. [CrossRef]

7. Zhu, F.; Hu, W.; Cao, J.; Sun, F.; Liu, Y.; Sun, Z. Micro/Nanoscale pore structure and fractal characteristics of tight gas sandstone: A case study from the Yuanba area, northeast Sichuan Basin, China. Mar. Pet. Geol. 2018, 98, 116-132. [CrossRef]

8. Sun, W.; Zuo, Y.; Wu, Z.; Liu, H.; Xi, S.; Shui, Y.; Wang, J.; Liu, R.; Lin, J. Fractal analysis of pores and the pore structure of the lower cambrian niutitang shale in northern Guizhou province: Investigations using NMR, SEM and image analyses. Mar. Pet. Geol. 2019, 99, 416-428. [CrossRef]

9. Clarkson, C.R.; Freeman, M.; He, L.; Agamalian, M.; Melnichenko, Y.B.; Mastalerz, M.; Bustin, R.M.; Radliński, A.P.; Blach, T.P. Characterization of tight gas reservoir pore structure using USANS/SANS and gas adsorption analysis. Fuel 2012, 95, 371-385. [CrossRef]

10. Clarkson, C.R.; Solano, N.; Bustin, R.M.; Bustin, A.M.M.; Chalmers, G.R.L.; He, L.; Melnichenko, Y.B.; Radliński, A.P.; Blach, T.P. Pore structure characterization of North American shale gas reservoirs using USANS/SANS, gas adsorption, and mercury intrusion. Fuel 2013, 103, 606-616. [CrossRef] 
11. Schmitt, M.; Fernandes, C.P.; Wolf, F.G.; Bellini Da Cunha Neto, J.A.; Rahner, C.P.; Santiago Dos Santos, V.S. Characterization of Brazilian tight gas sandstones relating permeability and angstrom-to micron-scale pore structures. J. Nat. Gas Sci. Eng. 2015, 27, 785-807. [CrossRef]

12. Lai, J.; Wang, G.; Fan, Z.; Chen, J.; Qin, Z.; Xiao, C.; Wang, S.; Fan, X. Three-Dimensional quantitative fracture analysis of tight gas sandstones using industrial computed tomography. Sci. Rep. UK 2017, 7, 1-12. [CrossRef] [PubMed]

13. Yao, Y.; Liu, D. Comparison of low-field NMR and mercury intrusion porosimetry in characterizing pore size distributions of coals. Fuel 2012, 95, 152-158. [CrossRef]

14. Dillinger, A.; Esteban, L. Experimental evaluation of reservoir quality in Mesozoic formations of the Perth Basin (Western Australia) by using a laboratory low field nuclear magnetic resonance. Mar. Pet. Geol. 2014, 57, 455-469. [CrossRef]

15. Daigle, H.; Johnson, A.; Thomas, B. Determining fractal dimension from nuclear magnetic resonance data in rocks with internal magnetic field gradients. Geophysics 2014, 79, D425-D431. [CrossRef]

16. Lai, J.; Wang, G.; Wang, Z.; Chen, J.; Pang, X.; Wang, S.; Zhou, Z.; He, Z.; Qin, Z.; Fan, X. A review on pore structure characterization in tight sandstones. Earth Sci. Rev. 2018, 177, 436-457. [CrossRef]

17. Paz Ferreiro, J.; Vidal Vázquez, E. Multifractal analysis of $\mathrm{Hg}$ pore size distributions in soils with contrasting structural stability. Geoderma 2010, 160, 64-73. [CrossRef]

18. Lai, J.; Wang, G.; Cao, J.; Xiao, C.; Wang, S.; Pang, X.; Dai, Q.; He, Z.; Fan, X.; Yang, L.; et al. Investigation of pore structure and petrophysical property in tight sandstones. Mar. Pet. Geol. 2018, 91, 179-189. [CrossRef]

19. Martínez, F.S.J.; Caniego, F.J.; García-Gutiérrez, C.; Espejo, R. Representative elementary area for multifractal analysis of soil porosity using entropy dimension. Nonlinear Proc. Geophys. 2007, 14, 503-511. [CrossRef]

20. Mandelbrot, B.B. Multifractal measures, especially for the geophysicist. Pure Appl. Geophys. PAGEOPH 1989, 131, 5-42. [CrossRef]

21. Muller, J.; McCauley, J.L. Implication of fractal geometry for fluid flow properties of sedimentary rocks. Transp. Porous Media 1992, 8, 133-147. [CrossRef]

22. Yao, Y.; Liu, D.; Tang, D.; Tang, S.; Huang, W.; Liu, Z.; Che, Y. Fractal characterization of seepage-pores of coals from China: An investigation on permeability of coals. Comput. Geosci. UK 2009, 35, 1159-1166. [CrossRef]

23. Yu, S.; Bo, J.; Pei, S.; Jiahao, W. Matrix compression and multifractal characterization for tectonically deformed coals by $\mathrm{Hg}$ porosimetry. Fuel 2018, 211, 661-675. [CrossRef]

24. Li, W.; Liu, H.; Song, X. Multifractal analysis of $\mathrm{Hg}$ pore size distributions of tectonically deformed coals. Int. J. Coal Geol. 2015, 144-145, 138-152. [CrossRef]

25. Liu, K.; Ostadhassan, M.; Zou, J.; Gentzis, T.; Rezaee, R.; Bubach, B.; Carvajal-Ortiz, H. Multifractal analysis of gas adsorption isotherms for pore structure characterization of the Bakken Shale. Fuel 2018, 219, 296-311. [CrossRef]

26. Ge, X.; Fan, Y.; Li, J.; Aleem Zahid, M. Pore structure characterization and classification using multifractal theory-An application in Santanghu basin of western China. J. Pet. Sci. Eng. 2015, 127, 297-304. [CrossRef]

27. Zheng, S.; Yao, Y.; Liu, D.; Cai, Y.; Liu, Y.; Li, X. Nuclear magnetic resonance T2 cutoffs of coals: A novel method by multifractal analysis theory. Fuel 2019, 241, 715-724. [CrossRef]

28. Zhao, P.; Wang, X.; Cai, J.; Luo, M.; Zhang, J.; Liu, Y.; Rabiei, M.; Li, C. Multifractal analysis of pore structure of middle Bakken formation using low temperature N2 adsorption and NMR measurements. J. Pet. Sci. Eng. 2019, 176, 312-320. [CrossRef]

29. Liu, K.; Ostadhassan, M.; Kong, L. Multifractal characteristics of Longmaxi Shale pore structures by N2 adsorption: A model comparison. J. Pet. Sci. Eng. 2018, 168, 330-341. [CrossRef]

30. Guan, M.; Liu, X.; Jin, Z.; Lai, J. The heterogeneity of pore structure in lacustrine shales: Insights from multifractal analysis using N2 adsorption and mercury intrusion. Mar. Pet. Geol. 2020, 114, 104150. [CrossRef]

31. Liu, K.; Ostadhassan, M.; Kong, L. Fractal and multifractal characteristics of pore throats in the Bakken Shale. Transp. Porous Media 2019, 126, 579-598. [CrossRef]

32. Hou, X.; Zhu, Y.; Chen, S.; Wang, Y.; Liu, Y. Investigation on pore structure and multifractal of tight sandstone reservoirs in coal bearing strata using LF-NMR measurements. J. Pet. Sci. Eng. 2020, 187, 106757. [CrossRef] 
33. Zhao, P.; Wang, Z.; Sun, Z.; Cai, J.; Wang, L. Investigation on the pore structure and multifractal characteristics of tight oil reservoirs using NMR measurements: Permian lucaogou formation in jimusaer sag, junggar basin. Mar. Pet. Geol. 2017, 86, 1067-1081. [CrossRef]

34. Liu, Y.; Zhang, J.; Tang, X. Predicting the proportion of free and adsorbed gas by isotopic geochemical data: A case study from lower Permian shale in the southern North China basin (SNCB). Int. J. Coal Geol. 2016, 156, 25-35. [CrossRef]

35. Tang, S.; Zhang, J.; Elsworth, D.; Tang, X.; Li, Z.; Du, X.; Yang, X. Lithofacies and pore characterization of the Lower Permian Shanxi and Taiyuan shales in the southern North China Basin. J. Nat. Gas Sci. Eng. 2016, 36, 644-661. [CrossRef]

36. Diao, Y.; Wei, J.; Li, Z.; Cao, H.; Li, X. Late carboniferous-early permian sequence stratigraphy and paleogeography in the southern North China Basin. J. Stratigr. 2011, 35, 88-94.

37. Liu, Y.; Tang, X.; Zhang, J.; Mo, X.; Huang, H.; Liu, Z. Geochemical characteristics of the extremely high thermal maturity transitional shale gas in the Southern North China Basin (SNCB) and its differences with marine shale gas. Int. J. Coal Geol. 2018, 194, 33-44. [CrossRef]

38. Dang, W.; Zhang, J.; Tang, X.; Chen, Q.; Han, S.; Li, Z.; Du, X.; Wei, X.; Zhang, M.; Liu, J.; et al. Shale gas potential of lower Permian marine-continental transitional black Shales in the Southern North China Basin, central China: Characterization of organic geochemistry. J. Nat. Gas Sci. Eng. 2016, 28, 639-650. [CrossRef]

39. Lai, J.; Wang, G.; Chai, Y.; Xin, Y.; Wu, Q.; Zhang, X.; Sun, Y. Deep burial diagenesis and reservoir quality evolution of high-temperature, high-pressure sandstones: Examples from Lower Cretaceous Bashijiqike formation in Keshen area, Kuqa depression, Tarim basin of China. AAPG Bull. 2017, 101, 829-862. [CrossRef]

40. Daigle, H.; Johnson, A. Combining mercury intrusion and nuclear magnetic resonance measurements using percolation theory. Transp. Porous Media 2016, 111, 669-679. [CrossRef]

41. Sigal, R.F. Pore-Size distributions for organic-Shale-Reservoir rocks from nuclear-magnetic- resonance spectra combined with adsorption measurements. SPE J. 2015, 20, 824-830. [CrossRef]

42. Caniego, F.J.; Martí, M.A.; San José, F. Rényi dimensions of soil pore size distribution. Geoderma 2003, 112, 205-216. [CrossRef]

43. Ge, X.; Fan, Y.; Zhu, X.; Chen, Y.; Li, R. Determination of nuclear magnetic resonance T2 cutoff value based on multifractal theory-An application in sandstone with complex pore structure. Geophysics 2015, 80, D11-D21. [CrossRef]

44. San José Martínez, F.; Martín, M.A.; Caniego, F.J.; Tuller, M.; Guber, A.; Pachepsky, Y.; García-Gutiérrez, C. Multifractal analysis of discretized X-ray CT images for the characterization of soil macropore structures. Geoderma 2010, 156, 32-42. [CrossRef]

45. Shao, X.; Pang, X.; Li, H.; Zhang, X. fractal analysis of pore network in tight gas sandstones using NMR method: A case study from the Ordos Basin, China. Energy Fuel 2017, 31, 10358-10368. [CrossRef]

46. Wang, R.; Shi, W.; Xie, X.; Zhang, W.; Qin, S.; Liu, K.; Busbey, A.B. Clay mineral content, type, and their effects on pore throat structure and reservoir properties: Insight from the Permian tight sandstones in the Hangjinqi area, north Ordos Basin, China. Mar. Pet. Geol. 2020, 115, 104281. [CrossRef]

47. Li, P.; Jia, C.; Jin, Z.; Liu, Q.; Zheng, M.; Huang, Z. The characteristics of movable fluid in the Triassic lacustrine tight oil reservoir: A case study of the Chang 7 member of Xin'anbian Block, Ordos Basin, China. Mar. Pet. Geol. 2019, 102, 126-137. [CrossRef]

48. Lai, J.; Wang, G.; Fan, Z.; Chen, J.; Wang, S.; Zhou, Z.; Fan, X. Insight into the pore structure of tight sandstones using NMR and HPMI measurements. Energy Fuel 2016, 30, 10200-10214. [CrossRef]

49. Zhang, P.; Lu, S.; Li, J.; Chen, C.; Xue, H.; Zhang, J. Petrophysical characterization of oil-bearing Shales by low-field nuclear magnetic resonance (NMR). Mar. Pet. Geol. 2018, 89, 775-785. [CrossRef]

50. Gao, H.; Li, H. Determination of movable fluid percentage and movable fluid porosity in ultra-low permeability sandstone using nuclear magnetic resonance (NMR) technique. J. Pet. Sci. Eng. 2015, 133, 258-267. [CrossRef]

51. Liu, M.; Xie, R.; Guo, J.; Jin, G. Characterization of pore structures of tight sandstone reservoirs by multifractal analysis of the NMRT2 distribution. Energy Fuel 2018, 32, 12218-12230. [CrossRef]

52. Lai, J.; Wang, G.; Fan, Z.; Zhou, Z.; Chen, J.; Wang, S. Fractal analysis of tight shaly sandstones using nuclear magnetic resonance measurements. AAPG Bull. 2018, 102, 175-193. [CrossRef] 
53. Loucks, R.G.; Reed, R.M.; Ruppel, S.C.; Jarvie, D.M. Morphology, genesis, and distribution of nanometer-scale pores in siliceous mudstones of the Mississippian Barnett Shale. J. Sediment. Res. 2009, 79, 848-861. [CrossRef]

54. Xiao, D.; Jiang, S.; Thul, D.; Lu, S.; Zhang, L.; Li, B. Impacts of clay on pore structure, storage and percolation of tight sandstones from the Songliao Basin, China: Implications for genetic classification of tight sandstone reservoirs. Fuel 2018, 211, 390-404. [CrossRef] 